\title{
Aprotinin Inhibits Thrombin Generation by Inhibition of the Intrinsic Pathway, but is not a Direct Thrombin Inhibitor
}

\author{
Ton Lisman $^{1}$ Jelle Adelmeijer ${ }^{1}$ Dana Huskens ${ }^{2}$ Joost C. M. Meijers ${ }^{3,4}$
}

${ }^{1}$ Surgical Research Laboratory, Department of Surgery, University of Groningen, University Medical Center Groningen, Groningen, The Netherlands

2 Department of Biochemistry, Cardiovascular Research Institute Maastricht (CARIM), Maastricht University, Synapse Research Institute, Maastricht, The Netherlands

TH Open 2021;5:e363-e375.

\author{
Address for correspondence Ton Lisman, PhD, Department of \\ Surgery, University Medical Center Groningen, BA44, Hanzeplein 1, \\ 9713 GZ Groningen, The Netherlands (e-mail: j.a.lisman@umcg.nl). \\ ${ }^{3}$ Department of Molecular Hematology, Sanquin Research, \\ Amsterdam, The Netherlands \\ ${ }^{4}$ Department of Experimental Vascular Medicine, Amsterdam UMC, \\ University of Amsterdam, Amsterdam, The Netherlands
}

\begin{abstract}
Keywords

- fibrinolysis

- aprotinin

- tranexamic acid

- thrombin

- platelets
\end{abstract}

Background Aprotinin is a broad-acting serine protease inhibitor that has been clinically used to prevent blood loss during major surgical procedures including cardiac surgery and liver transplantation. The prohemostatic properties of aprotinin likely are related to its antifibrinolytic effects, but other mechanisms including preservation of platelet function have been proposed.

Aim Here we assessed effects of aprotinin on various hemostatic pathways in vitro, and compared effects to tranexamic acid(TXA), which is an antifibrinolytic but not a serine protease inhibitor.

Methods We used plasma-based clot lysis assays, clotting assays in whole blood, plasma, and using purified proteins, and platelet activation assays to which aprotinin or TXA were added in pharmacological concentrations.

Results Aprotinin and TXA dose-dependently inhibited fibrinolysis in plasma. Aprotinin inhibited clot formation and thrombin generation initiated via the intrinsic pathway, but had no effect on reactions initiated by tissue factor. However, in the presence of thrombomodulin, aprotinin enhanced thrombin generation in reactions started by tissue factor. TXA had no effect on coagulation. Aprotinin did not inhibit thrombin, only weakly inhibited the TF-VIla complex and had no effect on platelet activation and aggregation by various agonists including thrombin. Aprotinin and TXA inhibited plasmin-induced platelet activation.

Conclusion Pharmacologically relevant concentrations of aprotinin inhibit coagulation initiated via the intrinsic pathway. The antifibrinolytic activity of aprotinin likely explains the prohemostatic effects of aprotinin during surgical procedures. The anticoagulant properties may be beneficial during surgical procedures in which pathological activation of the intrinsic pathway, for example by extracorporeal circuits, occurs. received

April 16, 2021

accepted after revision

June 29, 2021
DOI https://doi.org/

$10.1055 / \mathrm{s}-0041-1735154$.

ISSN 2512-9465. (c) 2021. The Author(s).

This is an open access article published by Thieme under the terms of the Creative Commons Attribution License, permitting unrestricted use, distribution, and reproduction so long as the original work is properly cited. (https://creativecommons.org/licenses/by/4.0/)

Georg Thieme Verlag KG, Rüdigerstraße 14, 70469 Stuttgart, Germany 


\section{Introduction}

Aprotinin is a broad acting serine protease inhibitor that has been clinically used to prevent blood loss during major surgical procedures including cardiac surgery and liver transplantation. ${ }^{1,2}$ The drug was withdrawn from clinical use in 2007, following a randomized controlled clinical trial that suggested aprotinin use in cardiac surgery was associated with an increased risk of complications and death. ${ }^{3}$ The comparator in these studies was a lysine analogue (either tranexamic acid or epsilon aminocaproic acid).

The effect of aprotinin in reducing perioperative blood loss is generally assumed to be related to its antifibrinolytic effect. ${ }^{4}$ Aprotinin is a direct inhibitor of plasmin, but also inhibits FXIIa-dependent activation of fibrinolysis by inhibiting kallikrein which activates factor XII in the contact pathway. By inhibition of kallikrein, aprotinin also inhibits activation of coagulation via the contact pathway. Finally, aprotinin has anti-inflammatory effects related to inhibition of kallikrein. A combined antifibrinolytic, anticoagulant, and anti-inflammatory effect of aprotinin is clinically evident by decreased D-dimer, prothrombin fragment $1+2$, and bradykinin plasma levels in patients undergoing cardiac surgery receiving aprotinin compared with those who did not. ${ }^{5-9}$ The antifibrinolytic effects of aprotinin may also reduce plasminmediated activation of platelets ${ }^{10,11}$ or plasmin-mediated proteolysis of platelet receptors such as glycoprotein $\mathrm{Ib},{ }^{12}$ thereby preserving platelet function.

As aprotinin is a broad-spectrum serine protease inhibitor, other targets that may explain the mode of action of aprotinin as a hemostatic drug have been proposed. It has even been questioned whether the antifibrinolytic effect is a main contributor to the prohemostatic effect of aprotinin. ${ }^{13}$ Other mechanisms that have been proposed to contribute to the prohemostatic properties of aprotinin are plasmin-independent platelet-preserving effects and anticoagulant properties, although it is not entirely clear how anticoagulant properties could contribute to a prohemostatic effect. Conflicting reports on these alternative modes of action of aprotinin have appeared in literature. For example, whereas some studies have reported that aprotinin inhibits platelet activation by a wide variety of agonists, ${ }^{14-16}$ other studies report that aprotinin inhibits platelet activation by thrombin but not by other agonists. ${ }^{17,18}$ Specifically, studies from one laboratory have shown that aprotinin in clinically relevant concentrations inhibits thrombin-mediated platelet activation via protease activated receptor (PAR)-1, but not via PAR4. ${ }^{17,19}$ This selective inhibition of PAR- 1 activation is not explained by direct thrombin inhibition of aprotinin, which would also block PAR-4 activation. In addition, one study has demonstrated that aprotinin is a direct thrombin inhibitor, ${ }^{18}$ but the $\mathrm{K}_{\mathrm{i}}$ reported (61 $\mathrm{uM}$ or $\sim 2900 \mathrm{KIU} / \mathrm{ml}$ ) is around an order of magnitude higher than peak plasma concentrations that are clinically observed (Plasma concentrations of aprotinin in patients undergoing cardiac or liver transplant surgery are between 100 and $400 \mathrm{KIU}^{20-23}$ ). Clinically, substantial evidence for a platelet-preserving effect of aprotinin exists, ${ }^{24-27}$ and although these platelet-preserving effects have been suggested to be mediated by direct effects of aprotinin on platelets, ${ }^{28}$ the effect may also be fully explained by a combination of inhibition of plasmin-mediated platelet activation ${ }^{10}$ and cleavage of platelet receptors, $^{12}$ and a decrease of thrombin generation via the intrinsic pathway. ${ }^{7}$ Also, it has been suggested that aprotinin is an inhibitor of the tissue factor-FVIIa complex, ${ }^{29}$ although the aprotinin doses used in this study were supratherapeutic.

To assess effects of aprotinin in clinically relevant concentrations on the hemostatic system, we have studied the effects of aprotinin in a range of in vitro assays using the currently marketed clinical product. Results were compared with tranexamic acid, which is an antifibrinolytic drug that is thought to reduce bleeding only by reducing plasmin formation.

\section{Materials and Methods}

\section{Materials}

Aprotinin was a generous gift from Nordic Pharma (Baarn, The Netherlands), tranexamic acid was from Mylan B.V. (Amstelveen, The Netherlands), Dabigatran was purchased from Alsachim (Illkirch Graffenstaden, France), recombinant tissue factor pathway inhibitor (TFPI) was from R\&D systems (Minneapolis, MI, USA). Pooled normal plasma was obtained by combining citrated plasma from $>200$ healthy volunteers.

\section{Clot Lysis Assay}

Fibrinolytic capacity in plasma was assessed by monitoring changes in turbidity during clot formation and lysis of a tissue factor-induced clot by exogenous tissue plasminogen activator, as described previously. ${ }^{30}$ Clot lysis time was defined as the time from the midpoint of the clear to maximum turbid transition, representing clot formation, to the midpoint of the maximum turbid to the clear transition, representing clot lysis (a typical example of a clot lysis curve can be found here ${ }^{31}$ ).

\section{PT|APTT}

Prothrombin time (PT) and activated partial thromboplastin time (APTT) assays were performed on an automated coagulation analyzer (STACompact 3, Stago, Breda, the Netherlands) with the use of reagents and protocols from the manufacturer.

\section{Thrombin Generation Test}

Thrombin generation assays were performed with the fluorimetric method calibrated automated thrombinography, as described previously by Hemker et al. ${ }^{32}$ Coagulation was activated using a diluted PT reagent (Innovin, Siemens, Erlangen, Germany, 1/900 final dilution), or a diluted APTT reagent (Synthasil, Werfen, Breda, The Netherlands, 1/40 dilution).The endogenous thrombin potential was derived with software from Thrombinoscope (Maastricht, the Netherlands). In selected experiments, thrombin generation was performed in the presence of soluble thrombomodulin (10 nM final concentration, Synapse, Maastricht, The Netherlands). 


\section{Viscoelastic Test}

Whole blood clot formation was assessed with the ClotPro analyser (Nodia, Breda, the Netherlands), a new generation viscoelastic test that is very similar to TEG and ROTEM (www. clot.pro). Clotting was initiated by commercially available reagents (Ex test and In test) for the extrinsic and intrinsic pathway.

\section{Chromogenic Assays}

In a 96-well plate, thrombin (Enzyme Research Laboratories, South Bend, IN, USA, $1 \mathrm{U} / \mathrm{ml}$ ) was mixed with Biophen Thrombin chromogenic substrate (Nodia, $1 \mathrm{mM}$ ) in Trisbuffered saline. Immediately after mixing, optical density at $405 \mathrm{~nm}$ was read every 10 seconds for 3 minutes in a VERSAmax reader (Molecular devices, San Jose, CA, USA) at $37^{\circ}$ Celcius. The initial slope of the time vs optical density curve reflects the amidolytic activity of thrombin. Similarly, the activity of recombinant factor XIa (purified as described, ${ }^{33} 10 \mathrm{nM}$ ), factor XIIa (Enzyme Research Laboratories, South Bend, IN, 19,5 $\mu \mathrm{M}$ ), kallikrein (Stago, $2 \mathrm{nM}$ ), and activated protein $C$ (a generous gift from the late Dr. Walter Kisiel, University of Albuquerque, New Mexico, $10 \mathrm{nM}$ ) were measured toward S2302 (kallikrein and FXIIa) or S2366 (XIa and activated protein $\mathrm{C}$ ) at a final concentration of $0.5 \mathrm{mM}$ (Chromogenix, Molndal, Sweden). The initial slope of the reactions without inhibitory compounds present was set at 100.

\section{Tissue Factor-factor VIla-mediated Activation of Factor $\mathbf{X}$}

In a 96-well plate, tissue factor (Innovin, 1/40 final dilution), was mixed with recombinant factor VIIa (Novo Nordisk, Bagsvaerd, Denmark, $20 \mathrm{ng} / \mathrm{ml}$ ) in Tris-buffered saline. Factor $\mathrm{X}$ was added (Bioconnect, the Netherlands, $10 \mathrm{ug} / \mathrm{ml}$ ) and incubated for 3 minutes at $37^{\circ}$ Celcius. Next, Pefachrome Xa (Stago, $1 \mathrm{mM}$ ) was added immediately thereafter, optical density at $342 \mathrm{~nm}$ was read every 10 seconds for 20 minutes in a VERSAmax reader at $37^{\circ} \mathrm{Celcius}$. The initial slope of the time vs optical density curve reflects the amount of factor Xa generated. The initial slope of the reactions without inhibitory compounds present was set at 100 .

\section{Fibrin Generation}

In a 96-well plate, thrombin $(1 \mathrm{U} / \mathrm{ml})$ was mixed with fibrinogen (Nodia, $2 \mathrm{mg} / \mathrm{ml}$ ) in Tris-buffered saline. Immediately after mixing, optical density at $340 \mathrm{~nm}$ was read every 10 seconds for 20 minutes in a VERSAmax reader. Clotting time was defined as the time from mixing to the midpoint of the clear to maximum turbid transition.

\section{Platelet Aggregation}

Platelet-rich plasma was prepared by a centrifugation of human whole blood at $180 \mathrm{~g}$ for 10 minutes. Washed platelets were prepared as described previously. ${ }^{34}$ Platelet-rich plasma was stimulated with collagen (Stago, Breda, The Netherlands, $2 \mu \mathrm{g} / \mathrm{ml}$ ). Washed platelets were stimulated by thrombin $(1 \mathrm{U} / \mathrm{ml})$ in the presence of GPRP peptide (Sigma-Aldrich,1 mM). Aggregation was moni- tored using a Chrono-Log Model 700 (Chronolog, Havertown, PA, USA).

\section{Platelet Activation}

Platelet activation in whole blood was studied by flow cytometry as described previously. ${ }^{35}$ In short, whole blood was diluted 1:3 with HEPES-buffered saline (HBS, $10 \mathrm{mmol} / \mathrm{l}$ HEPES, $150 \mathrm{mmol} / \mathrm{l} \mathrm{NaCl}, 1 \mathrm{mmol} / \mathrm{l} \mathrm{MgSO} 4,5 \mathrm{mmol} / \mathrm{l} \mathrm{KCl}$, $\mathrm{pH}$ 7.4). From this diluted blood, $5 \mu \mathrm{l}$ was added to each reaction mixture with a total volume of $20 \mu$ l. In this reaction mixture, $2 \mu$ l FITC-conjugated PAC-1, $1.5 \mu$ l PE-conjugated anti-P-selectin and $0.5 \mu \mathrm{l}$ APC-conjugated anti-CD42b was present. In addition, reaction mixtures contained the protease activated receptor (PAR)-1 agonist thrombin receptor activator peptide (TRAP-6 (SFLLRN), H-2936; Bachem, Germany, $30 \mu \mathrm{M}$ final concentration), the glycoprotein VI (GPVI) agonist collagen-related peptide (CRP, purchased from Professor Farndale, University of Cambridge, UK, $5 \mu-$ $\mathrm{g} / \mathrm{ml}$ final concentration), the $\mathrm{P} \mathrm{Y}_{12}$ agonist 2MeS-ADP (1624, Tocris, $2 \mu \mathrm{M}$ final concentration), thrombin (2 or $10 \mathrm{nM}$ in the presence of $1 \mathrm{mM}$ GPRP peptide, final concentrations), or plasmin $(100 \mu \mathrm{g} / \mathrm{ml})$. The reaction mixtures were incubated for exactly $20 \mathrm{~min}$ at $37^{\circ} \mathrm{C}$. Reactions were stopped by adding $250 \mu$ fixation solution $(137 \mathrm{mmol} / \mathrm{l} \mathrm{NaCl}$, $2.7 \mathrm{mmol} / \mathrm{l} \mathrm{KCl}, 1.12 \mathrm{mmol} / 1 \mathrm{NaH}_{2} \mathrm{PO}_{4}, 1.15 \mathrm{mmol} / 1 \mathrm{KH}_{2} \mathrm{PO}_{4}$, $10.2 \mathrm{mmol} / 1 \mathrm{Na}_{2} \mathrm{HPO}_{4}, 4 \mathrm{mmol} / \mathrm{l}$ EDTA, 0.5\% formaldehyde). An Accuri C6 (BD Biosciences, Erembodegem, Belgium) was used to analyze the samples. First, using the forward and sideward scatter pattern and gating on the CD42b positive cells, platelets were discriminated from other cells. Fluorescent intensity in the FITC gate and PE channels were determined and results are expressed as median fluorescent intensity (MFI) corrected for the MFI of blood to which no platelet agonist was added.

\section{Results}

\section{Aprotinin and Tranexamic Acid Inhibit Fibrinolysis in Plasma}

We first confirmed aprotinin and tranexamic acid to have potent and dose-dependent antifibrinolytic effects in vitro at clinically relevant concentrations. Aprotinin or tranexamic acid were added to pooled normal plasma which was subsequently tested in a plasma clot lysis assay. Both aprotinin and tranexamic acid dose-dependently increased clot lysis time, with no detectable lysis during the three hours the assay is run at the highest doses tested ( - Fig. 1). Aprotinin plasma levels between 100 and $400 \mathrm{KIU} / \mathrm{ml}^{20-23}$ and TXA plasma levels between 30 and $100 \mathrm{ug} / \mathrm{ml}^{36,37}$ have previously been measured in patients undergoing cardiac surgery or liver transplantation.

\section{Aprotinin Inhibits Coagulation Activated by the Intrinsic but not the Extrinsic Pathway}

Aprotinin and tranexamic acid were added to pooled normal plasma and plasma samples were tested in PT and APTT assays. Aprotinin dose-dependently prolonged the APTT but had no effect on the PT (-Fig. 2A, B). Tranexamic acid had no 

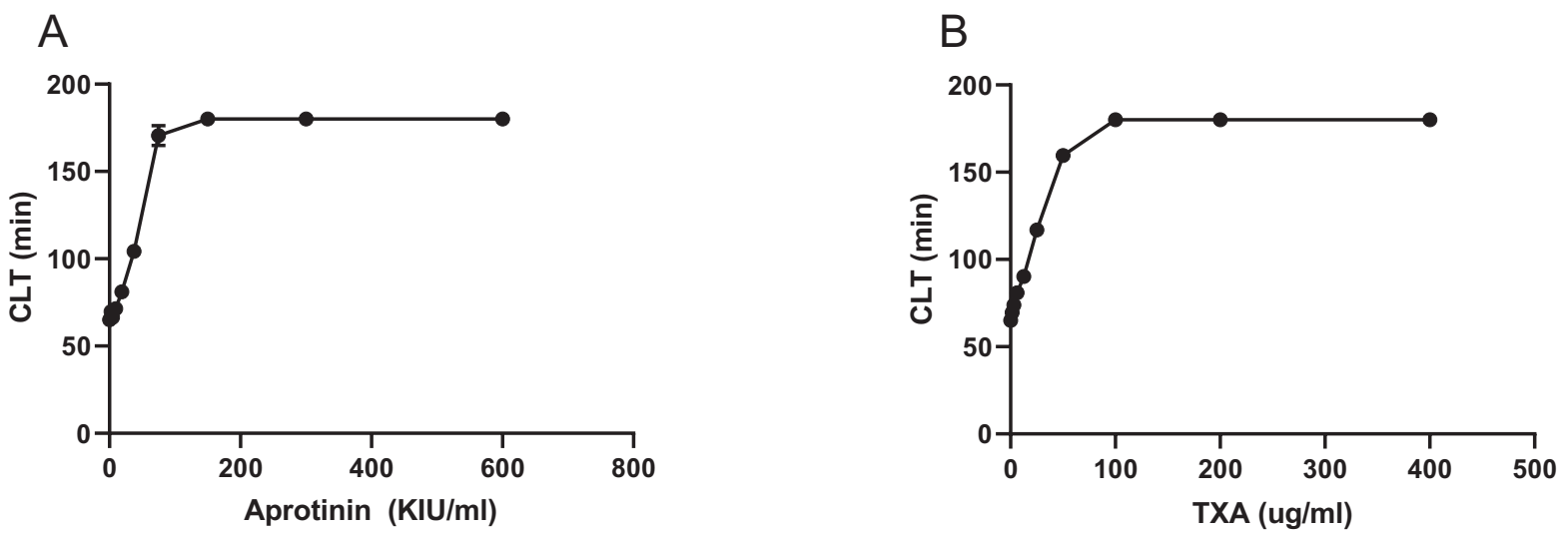

Fig. 1 The antifibrinolytic effect of aprotinin and tranexamic acid (TXA). Aprotinin or TXA were added to pooled normal plasma in increasing concentrations and clot lysis times were determined. Shown are mean values of 3 independent experiments. Error bars indicate standard deviations (but are not visible for the majority of data points as standard deviations were very low).

effect on both PT and APTT ( - Fig. 2C, D). Next, we performed thrombin generation tests in which coagulation was initiated by an APTT or a PT reagent. Aprotinin prolonged the lag time (data not shown) and decreased the ETP of a reaction initiated by an APTT reagent, but had no effect on thrombin generation when coagulation was initiated by a PT reagent (-Fig. 3A-B). Tranexamic acid had no effect on thrombin generation regardless of the initiating trigger ( - Fig. 3C-D). However, when thrombin generation experiments were performed in the presence of soluble thrombomodulin,
A
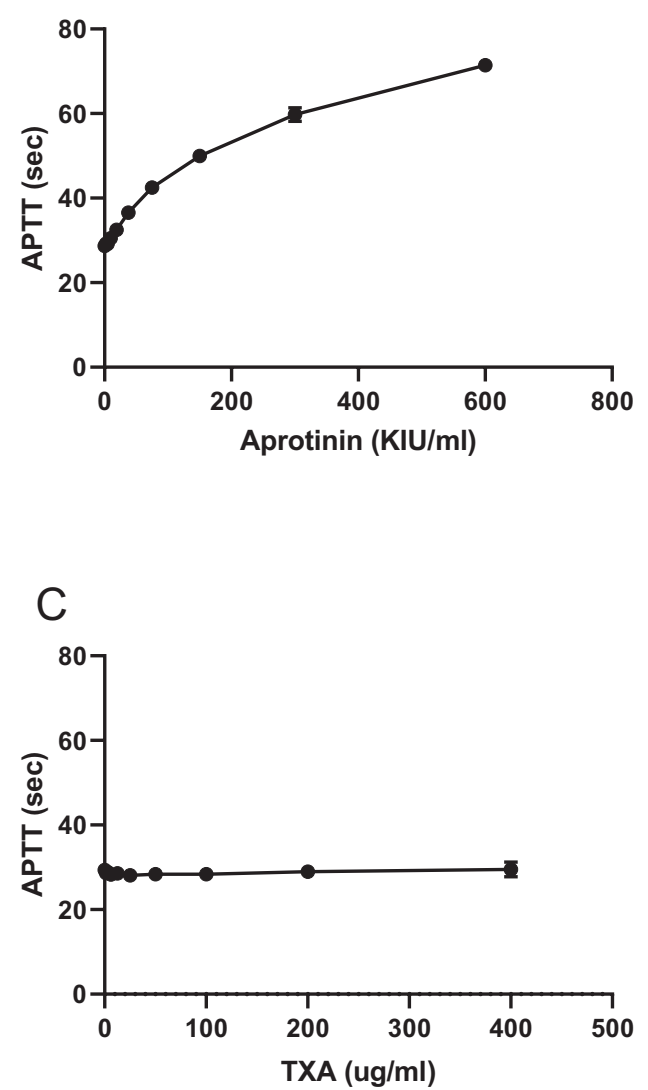

B
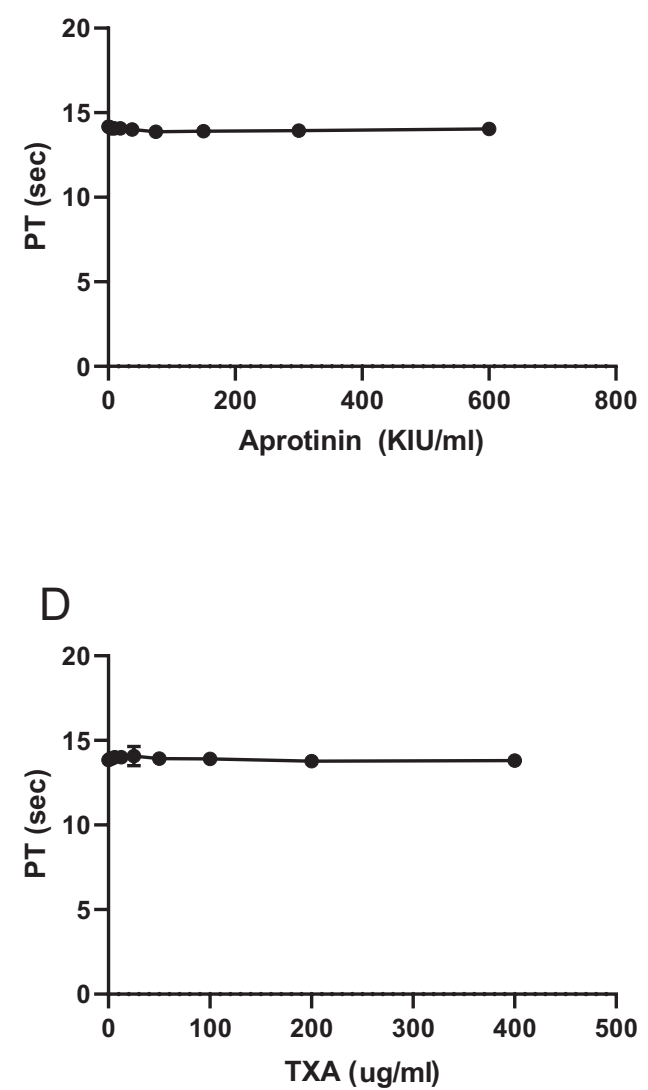

Fig. 2 Effects of aprotinin (A,B) and TXA (C,D) on the activated partial thromboplastin time (APTT, A,C) and prothrombin time (PT, B,D). Aprotinin and TXA were added to pooled normal plasma in increasing concentrations and APTT and PT assays were performed. Shown are mean values of 3 independent experiments. Error bars indicate standard deviations (but are not visible for the majority of data points as standard deviations were very low). 


\section{APTT reagent}
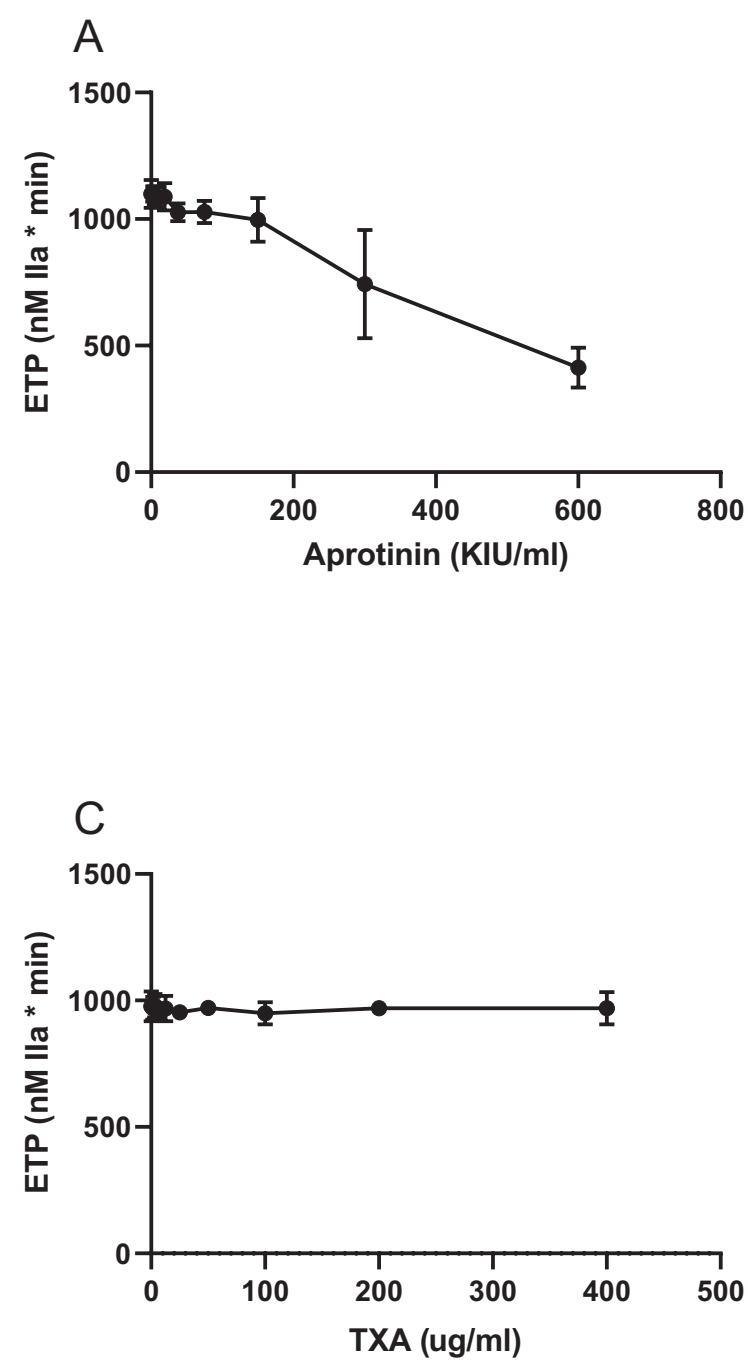

\section{PT reagent}
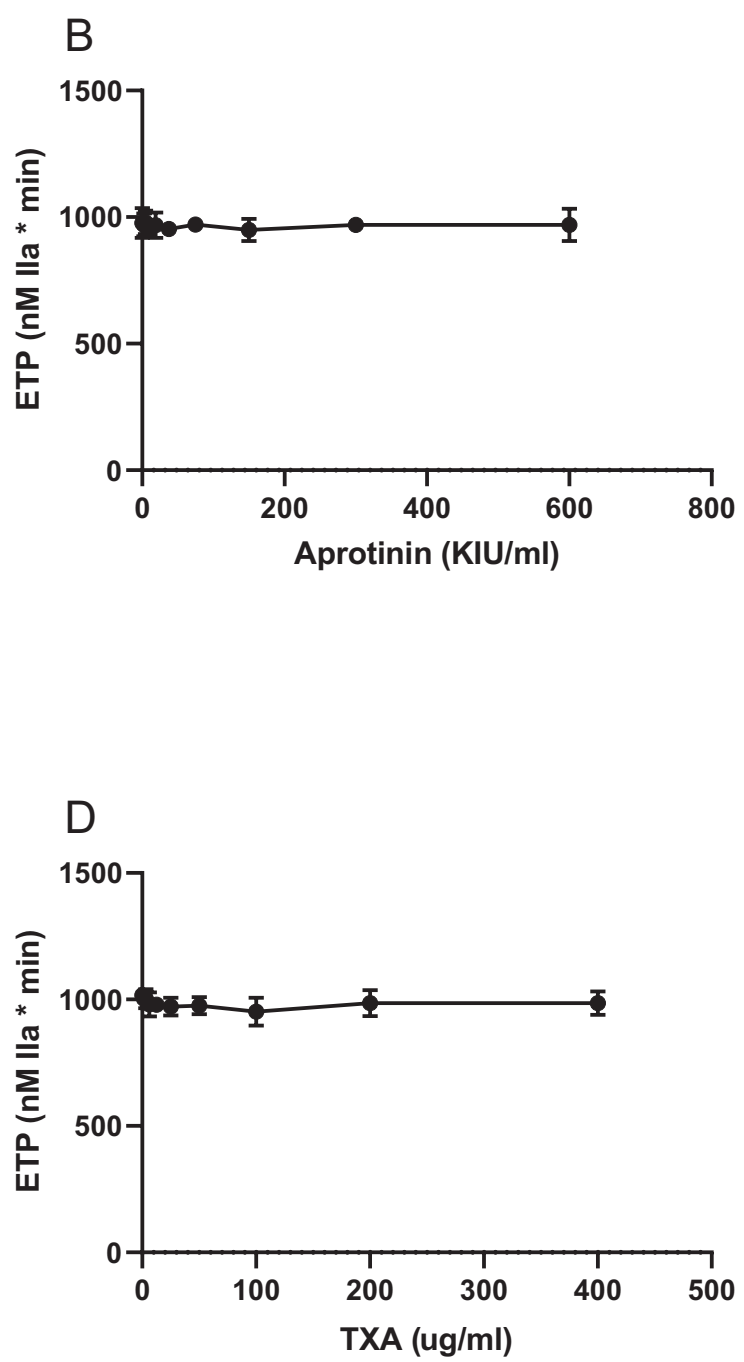

Fig. 3 Effects of aprotinin and TXA on the Endogenous Thrombin Potential (ETP). Aprotinin and TXA were added to pooled normal plasma in increasing concentrations and samples were subjected to calibrated automated thrombinography. Coagulation was initiated by a dilute APTT reagent ( $A$ and $C$ ) or a dilute PT reagent (B and D). Shown are mean ETP values derived from thrombin generation curves of 3 independent experiments. Error bars indicate standard deviations.

aprotinin still inhibited thrombin generation initiated by an APTT reagent, but stimulated thrombin generation initiated by a PT reagent (- Fig. 4). In a whole blood viscoelastic test, clot formation was inhibited by aprotinin only when clot formation was initiated by an activator of the intrinsic pathway (-Fig. 5). Aprotinin and tranexamic acid had no effect on maximal clot amplitude (data not shown). Aprotinin dose-dependently inhibited the activity of purified kallikrein and FXIa, but had limited effect on FXIIa. In addition, aprotinin dose-dependently inhibited activated protein C. Tranexamic acid did not inhibit kallikrein, FXIa, FXIIa, or activated protein C (-Fig. $\mathbf{6}$ ).

\section{Aprotinin is not an Inhibitor of Thrombin and only Weakly Inhibits the Tissue Factor-factor VIla Complex} We assessed the potential inhibitory effect of aprotinin on purified thrombin. First, we added aprotinin or dabigatran to thrombin in the presence of the chromogenic substrate S2238. Whereas aprotinin had no effect on the conversion of the chromogenic substrate by thrombin, dabigatran dosedependently inhibited the activity of thrombin toward the chromogenic substrate ( - Fig. 7A, B). Similarly, when thrombin was added to purified fibrinogen, aprotinin had no effect on clot formation, whereas dabigatran dose-dependently delayed clot formation ( $\mathbf{F i g}$. 7C, D). 


\section{APTT reagent}
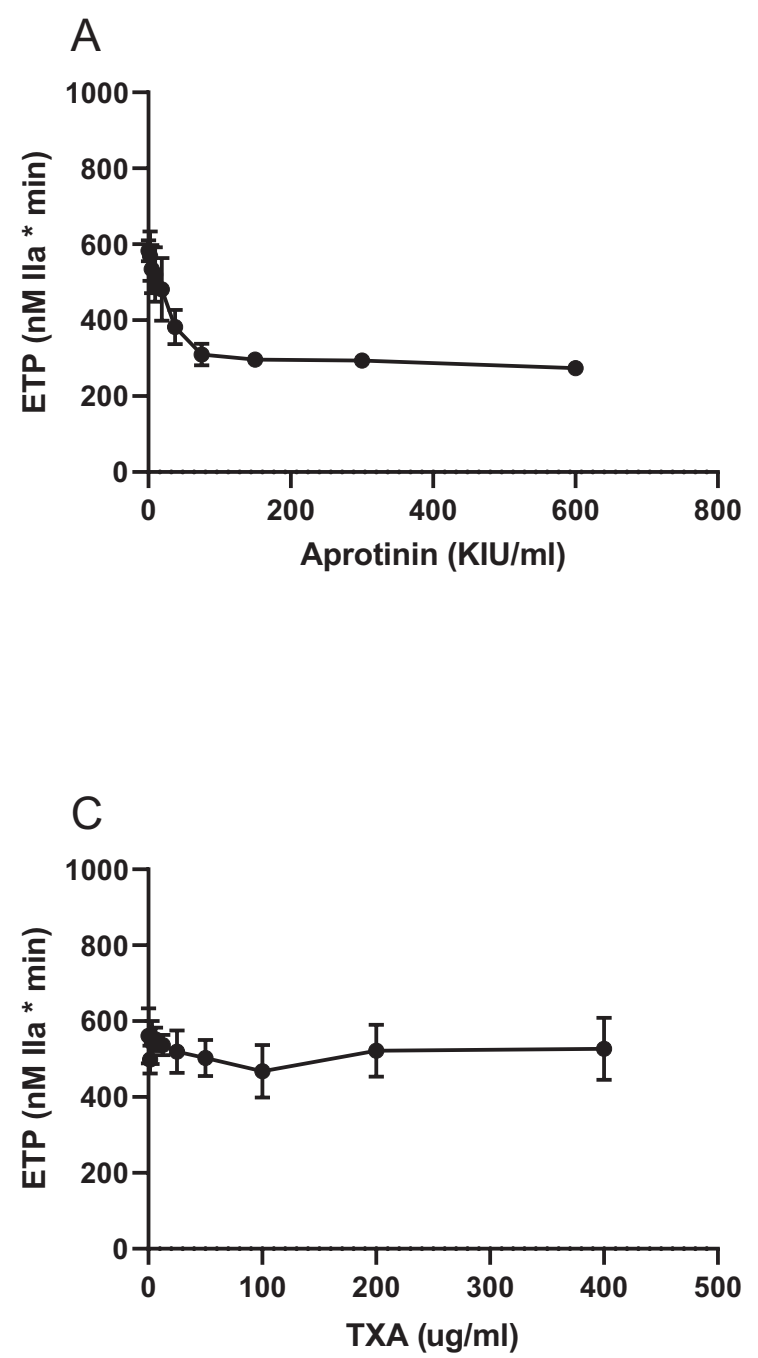

\section{PT reagent}
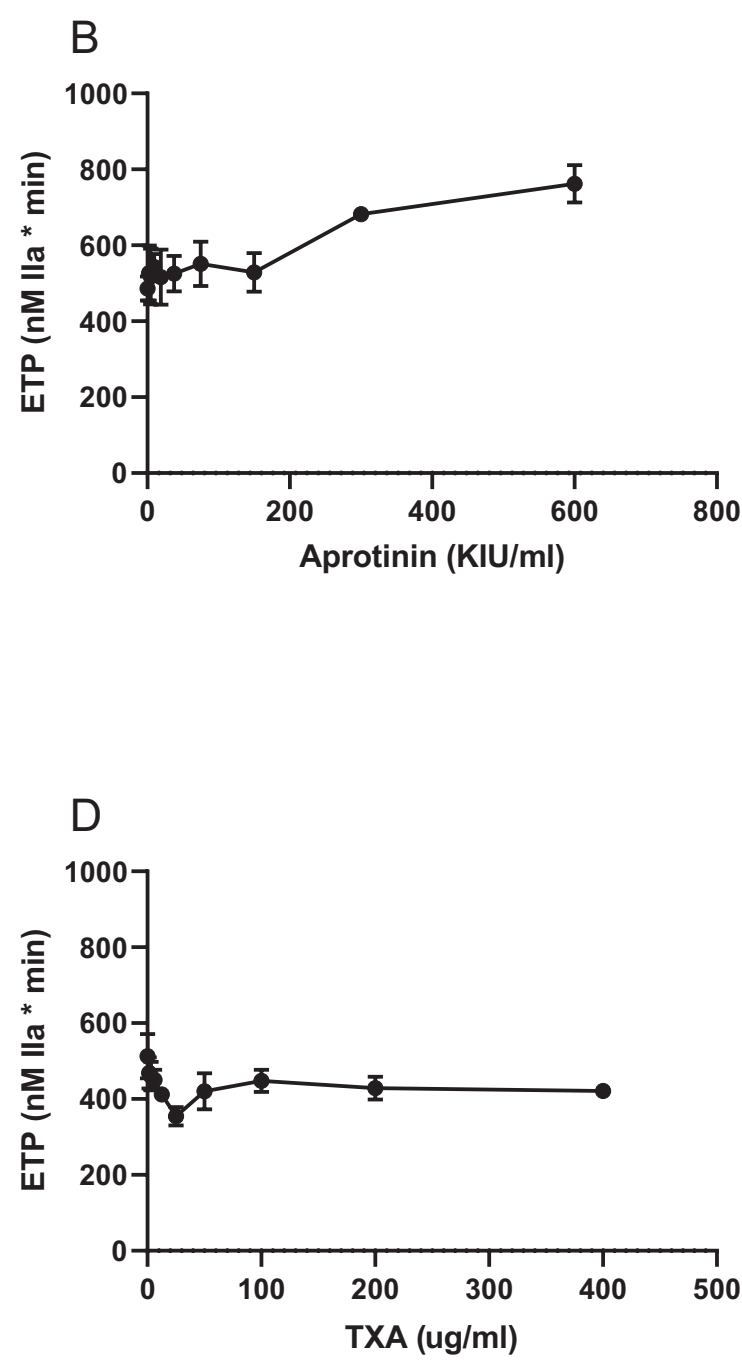

Fig. 4 Effects of aprotinin and TXA on the Endogenous Thrombin Potential (ETP) in the presence of soluble thrombomodulin. Aprotinin and TXA were added to pooled normal plasma in increasing concentrations and samples were subjected to thrombomodulin-modified calibrated automated thrombinography. Coagulation was initiated by a dilute APTT reagent (A and C) or a dilute PT reagent (B and D). Shown are mean ETP values derived from thrombin generation curves of 3 independent experiments. Error bars indicate standard deviations.

When aprotinin was added to a mixture of tissue factor, factor VIIa, and factor X, a slight decrease of FXa generation was observed at high aprotinin concentrations, whereas TFPI dose-dependently inhibited Xa generation $(7 \mathrm{E} / \mathrm{F})$.

\section{Aprotinin does not Inhibit Platelet Aggregation Induced by Thrombin or Collagen}

Washed platelets were stimulated with thrombin in the presence of GPRP, which prevents fibrin formation, and aggregation was monitored over time. As shown in -Fig. 8A, B, C, aprotinin or tranexamic acid did not prevent platelet aggregation by thrombin, but dabigatran dosedependently blocked aggregation. In platelet-rich plasma, aprotinin or TXA had no effect on collagen-induced aggregation (-Fig. 9A, B).

\section{Aprotinin Inhibits Platelet Activation by Plasmin, but has no Effect on Platelet Activation by Various Agonists}

When whole blood was stimulated with TRAP, CRP, 2MeSADP, or thrombin, aprotinin $(600 \mathrm{KIU} / \mathrm{ml})$ or tranexamic acid (400 ug/ml) had no effect on platelet activation as assessed by platelet P-selectin expression (-Fig. 10A) or PAC-1 binding ( - Fig. 10B), which reflects activation of integrin $\alpha$ IIb $\beta 3$. In contrast, both tranexamic acid and aprotinin fully blocked plasmin-induced platelet activation. 


\section{Intrinsic activation}

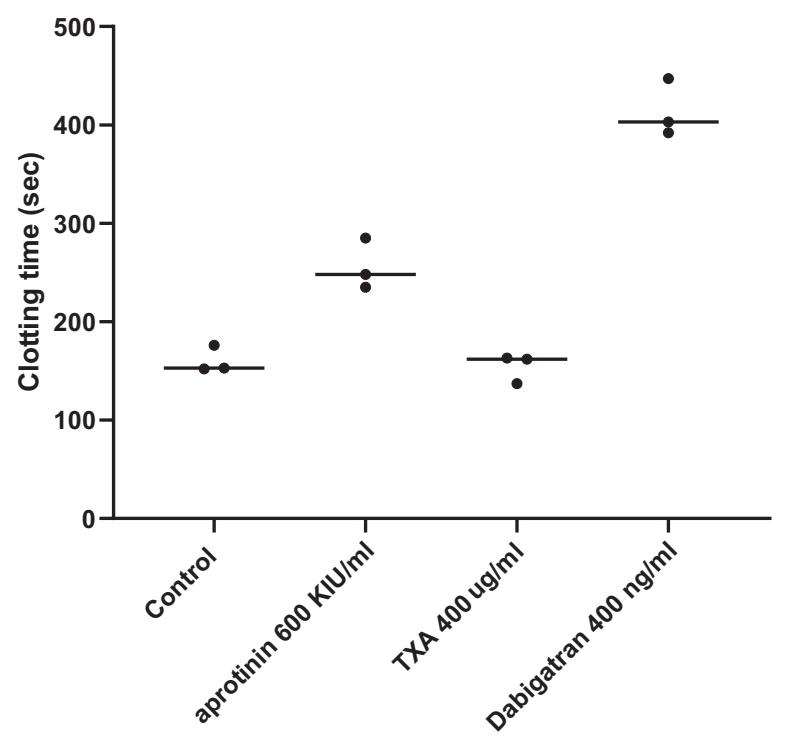

\section{Extrinsic activation}

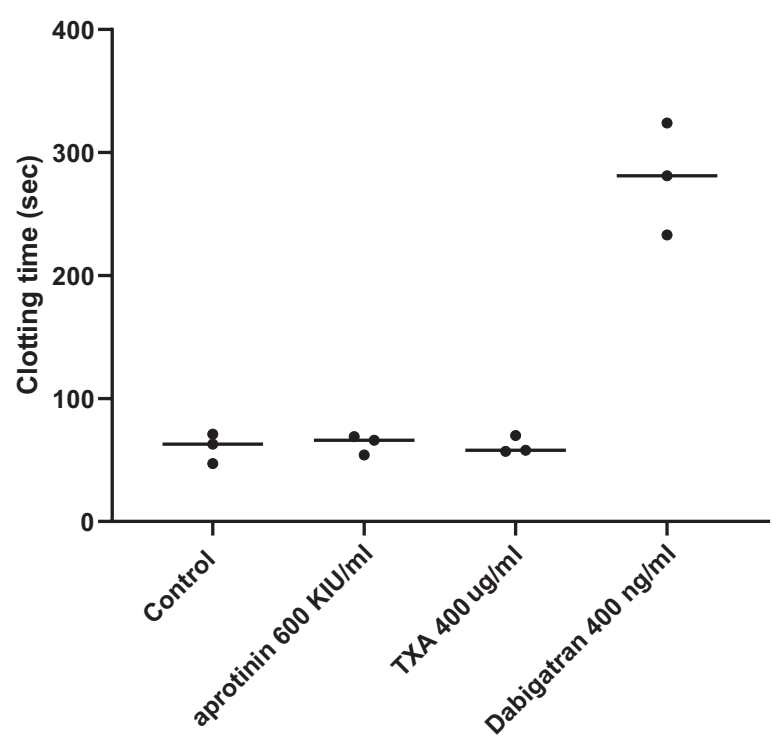

Fig. 5 Effects of aprotinin, TXA, and dabigatran on whole blood clot formation following intrinsic or extrinsic activation of coagulation. Aprotinin or TXA were added to whole blood from healthy individuals and clot formation was monitored in a ClotPro device following activation by the Ex test (panel A) or In test (panel B). Clot times of three donors are shown. Horizontal bars indicate medians.

\section{Discussion}

This study shows that aprotinin at clinically relevant concentrations has both antifibrinolytic and anticoagulant properties, and inhibits plasmin-induced platelet activation. The anticoagulant effect of aprotinin is restricted to inhibition of intrinsic activation mediated by inhibition of kallikrein and factor XIa. Under our experimental conditions, aprotinin did not inhibit thrombin, thrombin-mediated fibrinogen to fibrin conversion, or platelet activation by various agonists including thrombin, and only weakly inhibited the TF-VIla complex. The inhibitory effect on the purified TF-VIla complex is likely physiologically insignificant, as aprotinin did not inhibit TF-induced thrombin generation in plasma. Aprotinin increased thrombin generation via the extrinsic pathway in the presence of thrombomodulin, likely as a result of inhibition of activated protein C. ${ }^{38,39}$ However, as aprotinin decreases thrombin generation in vivo, ${ }^{5-7}$ it is unlikely this prohemostatic effect of aprotinin is clinically relevant. Collectively, our results suggest that plasmin and kallikrein are the only relevant hemostatic targets of aprotinin at clinically used concentrations in a plasma or whole blood environment. Tranexamic acid only had antifibrinolytic properties, and thus mechanistically, aprotinin has two theoretical advantages over tranexamic acid. First, the antiinflammatory properties via inhibition of kallikrein may be beneficial. Second, the inhibitory effects of aprotinin on intrinsic activation of coagulation may mean that undesired activation of coagulation, for example by cardiopulmonary bypass circuits, is prevented by aprotinin, whereas physiological hemostasis remains intact. Aprotinin thus may function as an anticoagulant that is antithrombotic without substantially increasing bleeding risk, similar to new-generation antithrombotic agents that target FXI or FXII. ${ }^{40}$

In our in vitro experiments, the antifibrinolytic and anticoagulant effects of aprotinin are apparent at plasma concentrations of $75 \mathrm{KIU}$ and higher. As the plasma concentrations of aprotinin in vivo (in patients undergoing cardiac or liver transplant surgery) are between 100 and 400 $\mathrm{KIU},{ }^{20-23}$ it is likely that the antifibrinolytic and anticoagulant effects of aprotinin described herein are clinically relevant. Indeed, aprotinin decreases plasma levels of D-dimer and prothrombin fragment $1+2$ in patients undergoing cardiac surgery. ${ }^{5-9}$

Our data are also in agreement with previous studies demonstrating in vivo platelet-preserving effects of aprotinin. ${ }^{24-27}$ By inhibition of plasmin, aprotinin prevents or decreases plasmin-mediated proteolysis of platelet receptors and plasmin-mediated platelet activation. In addition, by inhibition of thrombin generation via the intrinsic pathway, aprotinin may also prevent platelet activation.

We do not confirm previous data on direct inhibitory effects of aprotinin on platelet activation, and do not find aprotinin to be a relevant thrombin inhibitor at the doses tested (up to $600 \mathrm{KIU} / \mathrm{ml}$, which is supratherapeutic), which is in line with the $K_{i}$ of $61 \mathrm{uM}$ or $2900 \mathrm{KIU} / \mathrm{ml}$ previously reported. Why we fail to find inhibitory effects of aprotinin on thrombin-induced platelet activation, or on platelet activation induced by other agonists is not entirely clear. We thus have no clear explanation for the divergent results with previous studies but do note that 1 ) the high $K_{i}$ for thrombin does not readily explain why aprotinin at clinically relevant concentrations would inhibit thrombin-mediated platelets activation and 2) previous studies on the inhibitory effect of 

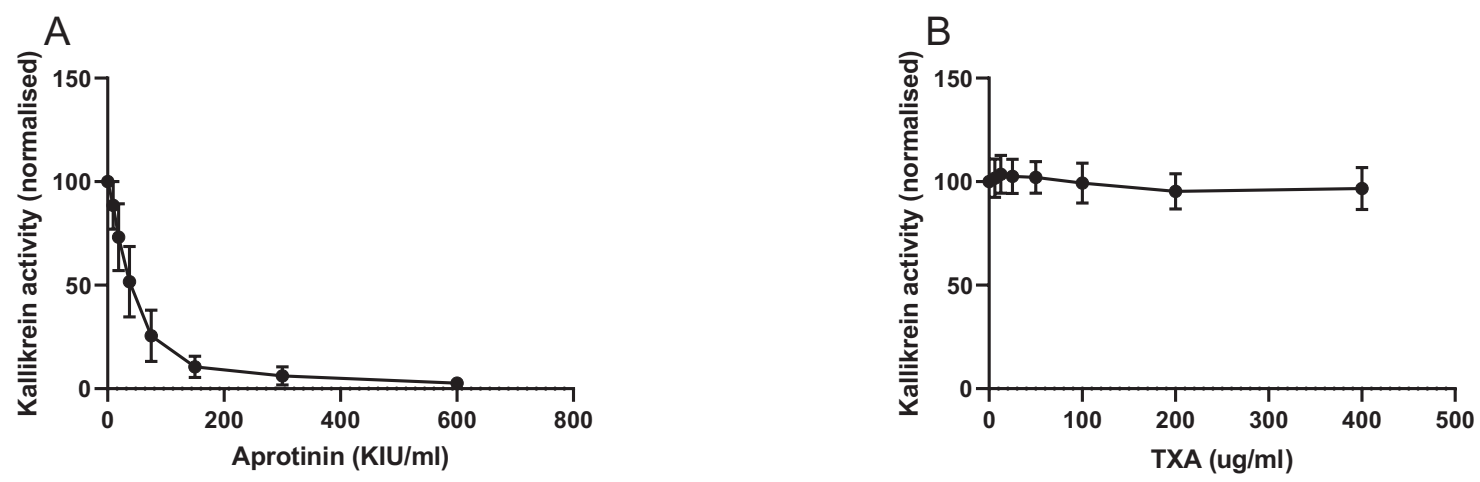

C

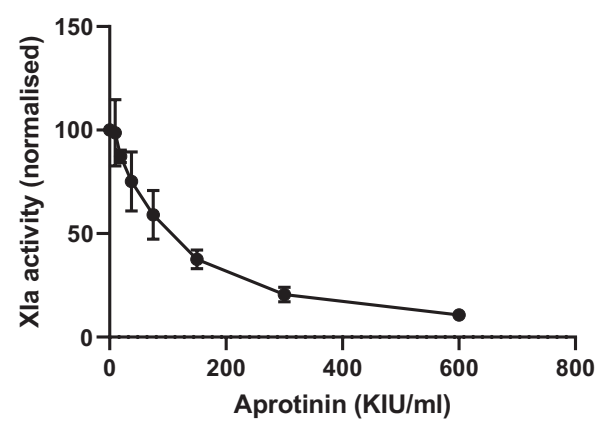

D

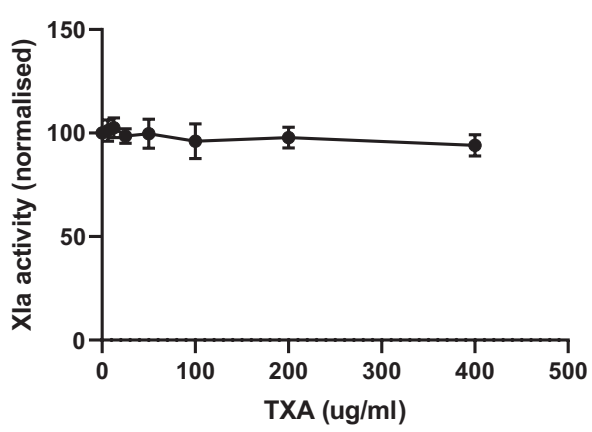

E
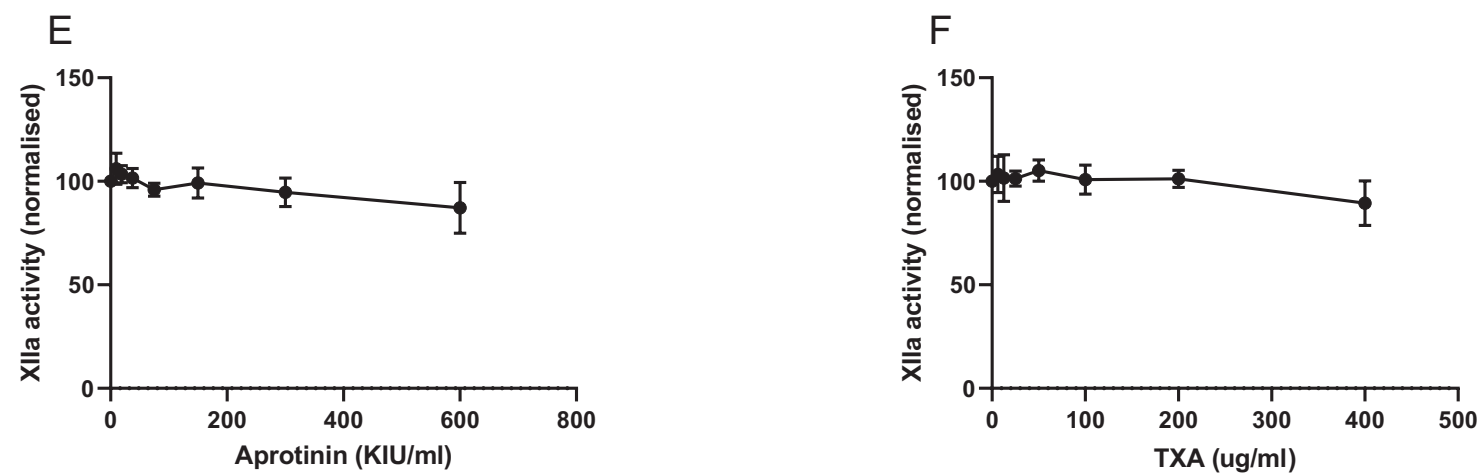

$\mathrm{H}$
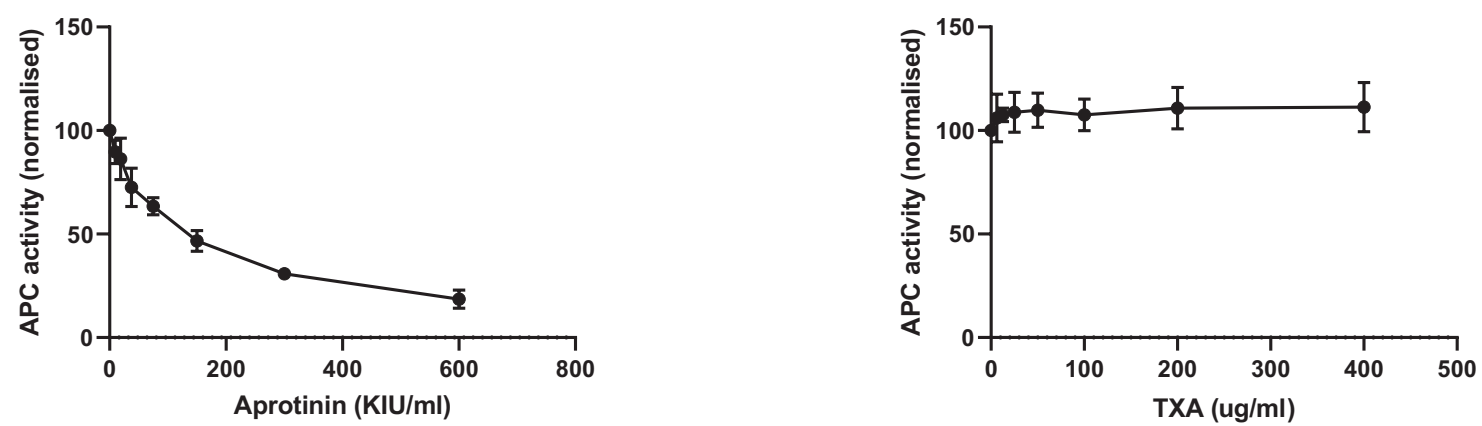

Fig. 6 Effects of aprotinin and TXA on kallikrein, factor Xla, factor XIla, and activated protein C. Aprotinin or TXA were added in increasing concentrations to purified activated coagulation factors, after which enzyme activities were determined using a chromogenic substrate. Activity levels in the absence of aprotinin or TXA were set at 100. Shown are mean values of 3 independent experiments performed in duplicate. 
A

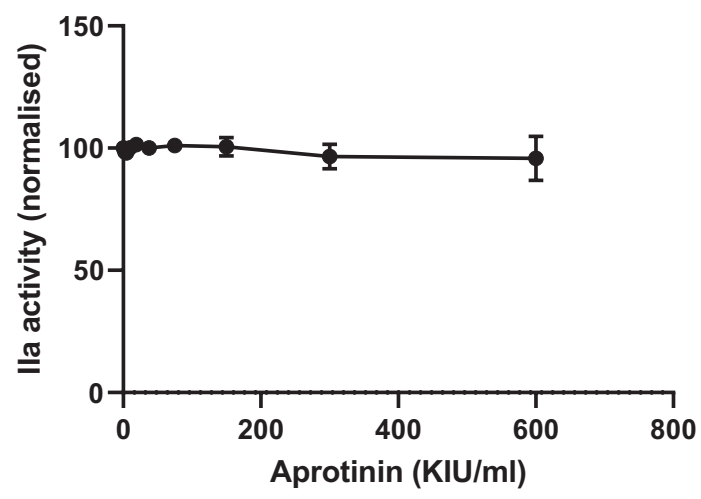

C

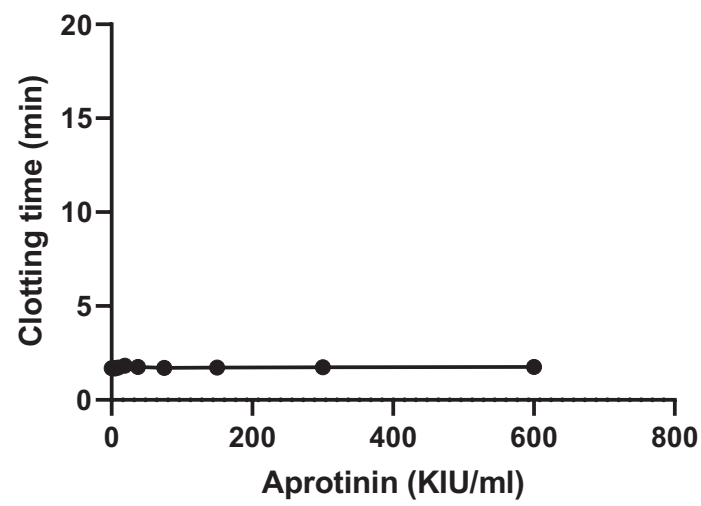

$E$

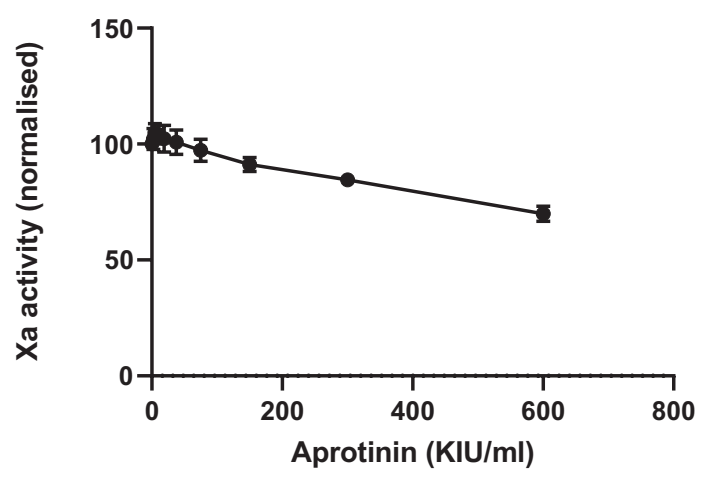

B

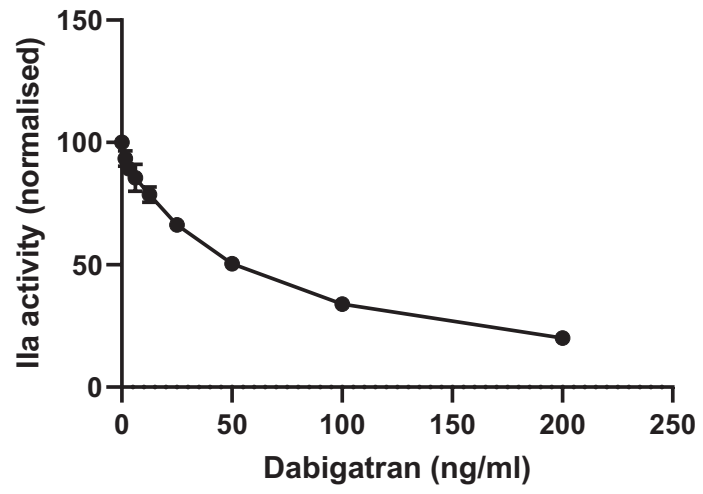

D

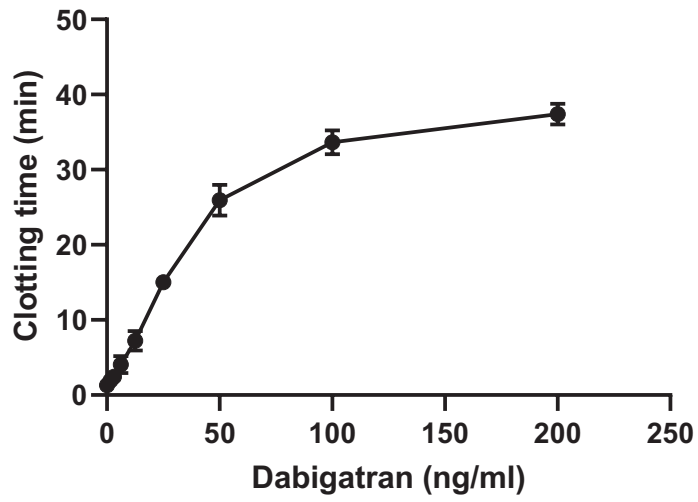

$\mathrm{F}$

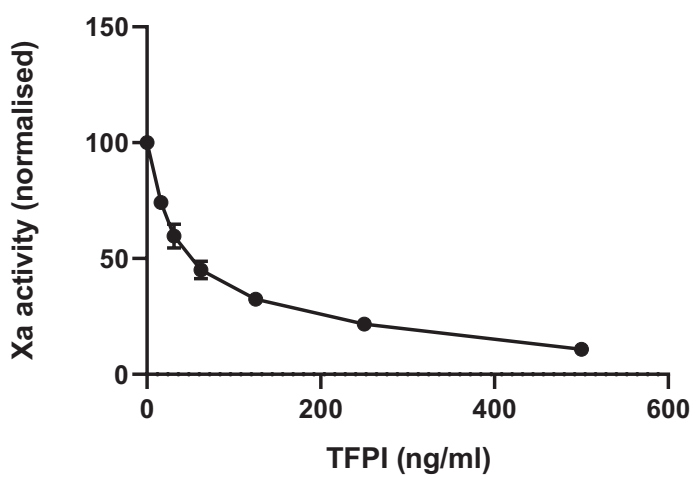

Fig. 7 Effects of aprotinin on thrombin and the tissue factor-factor Vlla complex. A and B: Aprotinin or dabigatran were added in increasing concentrations to purified thrombin after which thrombin activity was assessed using the chromogenic substrate S2238. C and D: aprotinin and dabigatran were added in increasing concentrations to purified fibrinogen, after which thrombin was added. Clot formation was monitored by turbidity measurements over time. E and F: Aprotinin or TFPI were added to the tissue factor-factor VIla complex in the presence of factor $X$ and factor $X$ a generation over time was assessed using a chromogenic substrate. Shown are mean values of 3 independent experiments. Error bars indicate standard deviations (but are not visible for the majority of data points as standard deviations were very low). 

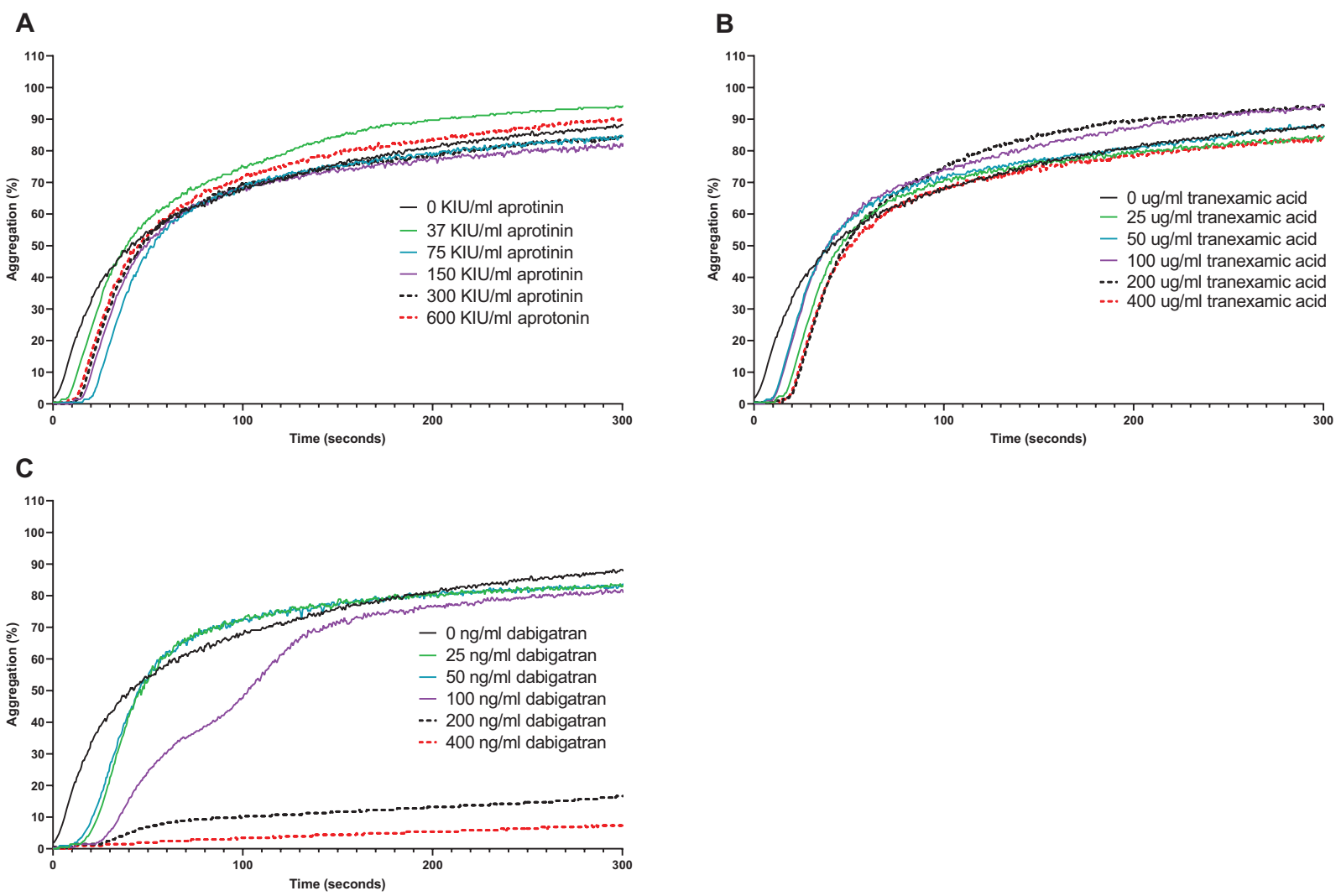

Fig. 8 Effects of aprotinin and TXA on thrombin-induced platelet aggregation. Aprotinin (panel A), tranexamic acid (panel B), or dabigatran (panel C) were added in increasing concentrations to washed human platelets after which platelet aggregation was initiated by addition of $1 \mathrm{U} / \mathrm{ml}$ of thrombin. Shown is a representative example of experiments performed with three different platelet donors.
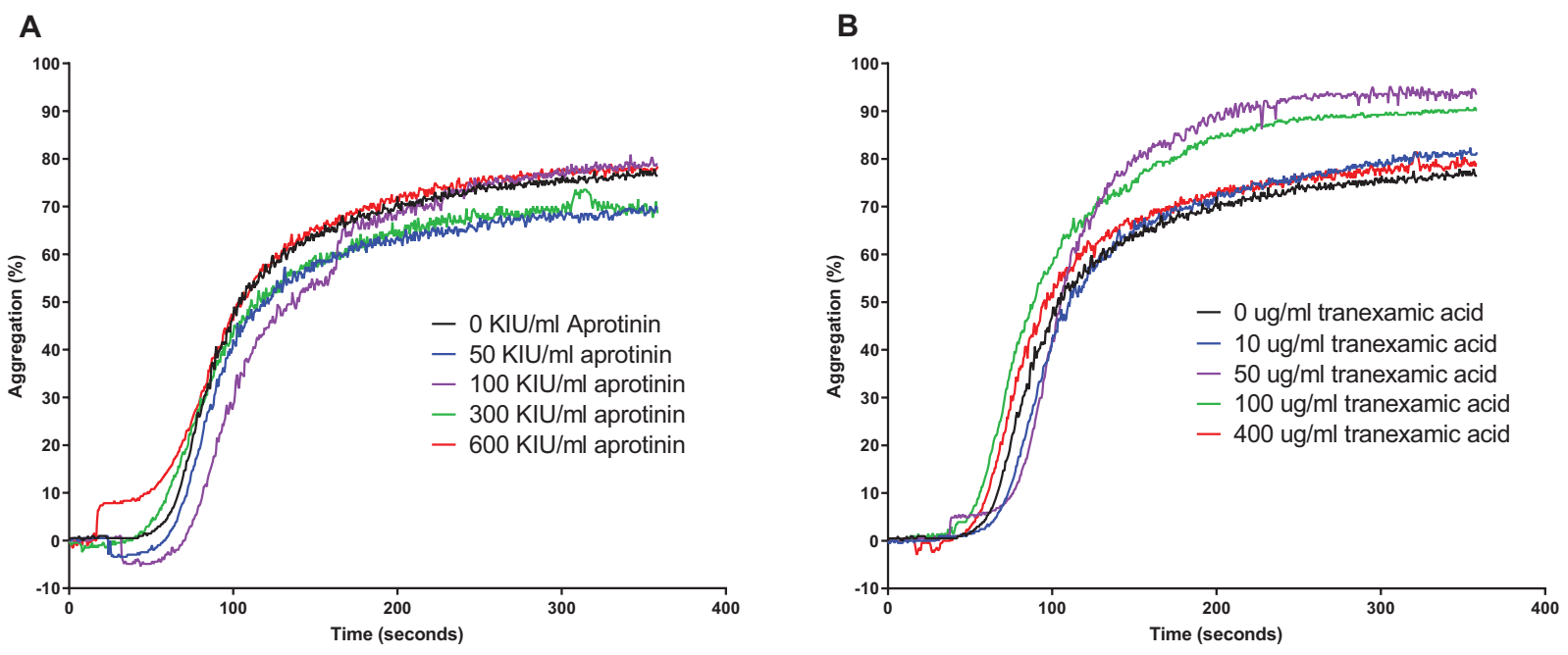

Fig. 9 Effects of aprotinin and TXA on collagen-induced platelet aggregation. Aprotinin (panel A), or tranexamic acid (panel B) were added in increasing concentrations to human platelet-rich plasma after which platelet aggregation was initiated by addition of $2 \mathrm{ug} / \mathrm{ml}$ of collagen. Shown is a representative example of experiments performed with three different donors.

aprotinin on the direct thrombin-independent platelet inhibitory properties also yielded contradictory results. ${ }^{14-17,19}$

Taken together, our in vitro studies show that aprotinin has both antifibrinolytic and anticoagulant activity at clinically relevant concentrations. We propose that the antifibrinolytic activity is primarily responsible for the prohemostatic effects of aprotinin during surgical proce- dures. In addition, we propose that the anticoagulant properties may be beneficial in clinical situations in which substantial activation of the intrinsic pathway of coagulation occurs. As aprotinin is a selective inhibitor of intrinsic coagulation activation, it will dampen undesired coagulation activation by, for example extracorporeal circuits, without interfering with physiological hemostasis, and will therefore 
A

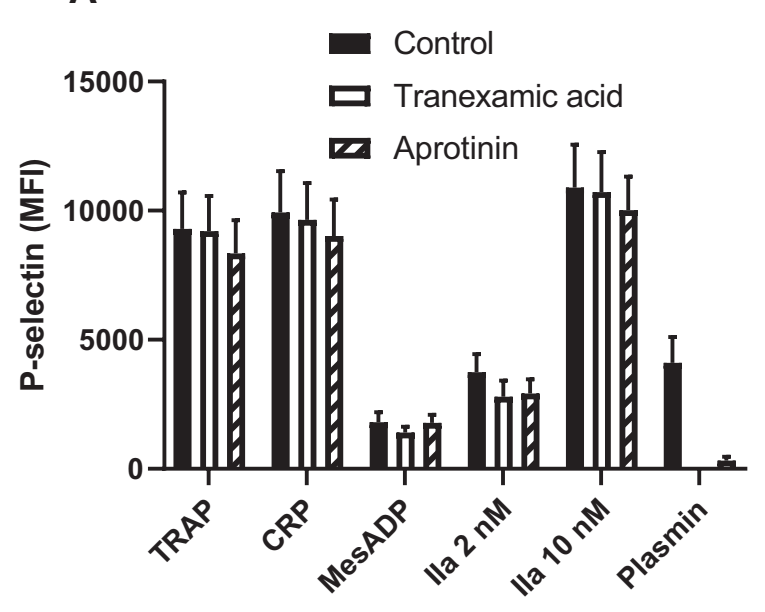

B

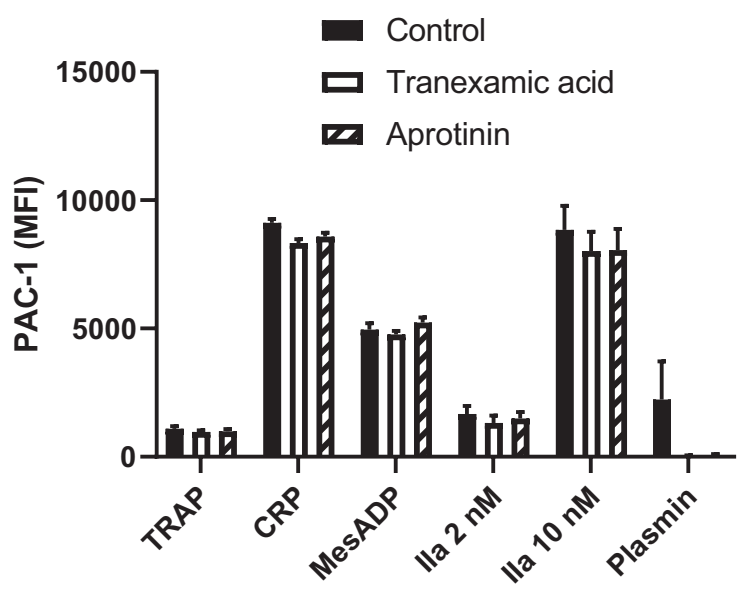

Fig. 10 Effects of aprotinin and TXA on platelet activation by thrombin receptor activating peptide (TRAP), collagen-related peptide (CRP),2MeS-ADP, thrombin (Ila), and plasmin. Diluted whole blood was stimulated with one of the mentioned agonists or vehicle, and P-selectin expression (panel A) or activation of $\alpha$ llb 33 (panel B) were assessed by flow cytometry using anti-P-selectin or the PAC-1 antibody. Shown are median fluorescence intensity (MFI) corrected for values obtained in unstimulated samples. Bars indicate means of three independent experiments each performed in triplicate, error bars indicate standard deviations.

not contribute to perioperative bleeding. Aprotinin has now carefully been reintroduced, but may have clinical applications beyond complex cardiac surgery. For example, the anticoagulant properties of aprotinin may be exploited in clinically challenging situations in which activation of the intrinsic pathway leads to thrombotic events. Such scenarios include extracorporeal circuits used outside cardiac surgery, such as ECMO. As we have shown that aprotinin is not a direct thrombin or platelet inhibitor, aprotinin is not expected to increase bleeding risk in these scenarios.

\section{What is Known}

- Aprotinin is a clinically used antifibrinolytic with an incompletely characterized mode of action

- Aprotinin is an inhibitor of plasmin but also inhibits kallikrein which leads to inhibition of intrinsically activated coagulation and of inflammation

- Other proposed targets of aprotinin are the tissue factor-VIIa complex, thrombin, platelets, and protease activated receptor 1 on platelets

\section{What this Study Adds}

- We studied hemostatic effects of aprotinin in various in vitro models

- Aprotinin inhibits fibrinolysis and the intrinsic pathway of coagulation, but does not inhibit platelet function, thrombin, or TF-VIIa

- The anticoagulant properties of aprotinin might be beneficial during surgeries using extracorporeal circuits

\section{Author Contributions}

TL: Designed the study, supervised experimental work, analyzed and interpreted data, wrote the manuscript; JA: Performed, analyzed and interpreted experiments, revised the manuscript; DH: Performed, analyzed and interpreted experiments, revised the manuscript; JCMM: Designed the study, interpreted data, revised the manuscript. All authors approved the final version of the manuscript.

Funding

This study was sponsored in part by an unrestricted educational grant of Nordic Pharma to TL. In addition, this collaboration project is co-financed by the Ministry of Economic Affairs and Climate Policy of the Netherlands by means of the PPP-allowance made available by the Top Sector Life Sciences \& Health to stimulate public-private partnerships.

\section{Conflicts of Interest}

This study was sponsored in part by an unrestricted educational grant of Nordic Pharma to TL. The other authors have no conflicts of interest to report.

\section{References}

1 Levi M, Cromheecke ME, de Jonge E, et al. Pharmacological strategies to decrease excessive blood loss in cardiac surgery: a meta-analysis of clinically relevant endpoints. Lancet 1999;354 (9194):1940-1947 https://pubmed.ncbi.nlm.nih.gov/10622296/

2 Molenaar IQ Warnaar N, Groen H, Tenvergert EM, Slooff MJH, Porte RJ. Efficacy and safety of antifibrinolytic drugs in liver transplantation: a systematic review and meta-analysis. [Internet]Am J Transplant 2007;7(01):185-194 https://pubmed.ncbi. nlm.nih.gov/17227567/ 
3 Fergusson DA, Hébert PC, Mazer CD, et al; BART Investigators. A comparison of aprotinin and lysine analogues in high-risk cardiac surgery. N Engl J Med 2008;358(22):2319-2331 https://pubmed. ncbi.nlm.nih.gov/18480196/

4 Orchard MA, Goodchild CS, Prentice CRM, et al. Aprotinin reduces cardiopulmonary bypass-induced blood loss and inhibits fibrinolysis without influencing platelets. Br J Haematol 1993;85(03): 533-541 https://pubmed.ncbi.nlm.nih.gov/7510990/

5 Speekenbrink RGH, Wildevuur CRH, Sturk A, Eijsman L. Low-dose and high-dose aprotinin improve hemostasis in coronary operations. J Thorac Cardiovasc Surg 1996;112(02):523-530 https:// pubmed.ncbi.nlm.nih.gov/8751522/

6 Kaminishi Y, Hiramatsu Y, Watanabe Y, Yoshimura Y, Sakakibara Y. Effects of nafamostat mesilate and minimal-dose aprotinin on blood-foreign surface interactions in cardiopulmonary bypass Ann Thorac Surg 2004;77(02):644-650 https://pubmed.ncbi. nlm.nih.gov/14759453/

7 Santamaría A, Mateo J, Oliver A, et al. The effect of two different doses of aprotinin on hemostasis in cardiopulmonary bypass surgery: similar transfusion requirements and blood loss. Haematologica 2000;85(12):1277-1284 https://pubmed.ncbi.nlm. nih.gov/11114135/

8 Campbell DJ, Dixon B, Kladis A, Kemme M, Santamaria JD. Activation of the kallikrein-kinin system by cardiopulmonary bypass in humans. Am J Physiol Regul Integr Comp Physiol 2001;281(04): R1059-R1070 https://pubmed.ncbi.nlm.nih.gov/11557611/

9 Dietrich W. Reducing thrombin formation during cardiopulmonary bypass: is there a benefit of the additional anticoagulant action of aprotinin? J Cardiovasc Pharmacol 1996;27(27, Suppl 1) S50-S57 https://pubmed.ncbi.nlm.nih.gov/8938284/

10 Shigeta O, Kojima H, Jikuya T, et al. Aprotinin inhibits plasmininduced platelet activation during cardiopulmonary bypass. Circulation 1997;96(02):569-574 https://pubmed.ncbi.nlm.nih. gov/9244227/

11 Watabe A, Ohta M, Matsuyama N, et al. Characterization of plasmin-induced platelet aggregation. Res Commun Mol Pathol Pharmacol 1997;96(03):341-352 https://pubmed.ncbi.nlm.nih. gov/9261893/

12 Adelman B, Michelson AD, Greenberg J, Handin RI. Proteolysis of platelet glycoprotein Ib by plasmin is facilitated by plasmin lysine-binding regions. Blood 1986;68(06):1280-1284 https:// pubmed.ncbi.nlm.nih.gov/2946332/

13 Royston D. Thoughts on the Mechanism of Action of Aprotinin. Transfus Altern Transfus Med 2005;7(01):29-36 Available from https://onlinelibrary.wiley.com/doi/full/10.1111/j.1778-428X. 2005.tb00152.x

14 Aoki N, Naito K, Yoshida N. Inhibition of platelet aggregation by protease inhibitors. Possible involvement of proteases in platelet aggregation. Blood 1978;52(01):1-12 https://pubmed.ncbi.nlm. nih.gov/656619/

15 Kozek-Langenecker SA, Mohammad SF, Masaki T, Green W, Kamerath C, Cheung AK. The effects of aprotonin on platelets in vitro using whole blood flow cytometry. Anesth Analg 2000;90 (01):12-16 https://pubmed.ncbi.nlm.nih.gov/10624968/

16 Khan TA, Bianchi C, Voisine P, Sandmeyer J, Feng J, Sellke FW. Aprotinin inhibits protease-dependent platelet aggregation and thrombosis. Ann Thorac Surg 2005;79(05):1545-1550 https:// pubmed.ncbi.nlm.nih.gov/15854931/

17 Poullis M, Manning R, Laffan M, Haskard DO, Taylor KM, Landis RC. The antithrombotic effect of aprotinin: actions mediated via the proteaseactivated receptor 1. J Thorac Cardiovasc Surg 2000;120 (02):370-378 https://pubmed.ncbi.nlm.nih.gov/10917956/

18 Pintigny D, Dachary-Prigent J. Aprotinin can inhibit the proteolytic activity of thrombin. A fluorescence and an enzymatic study. Eur J Biochem 1992;207(01):89-95 https://pubmed.ncbi.nlm. nih.gov/1378406/

19 Day JRS, Haskard DO, Taylor KM, Landis RC. Effect of aprotinin and recombinant variants on platelet protease-activated receptor 1 activation. Ann Thorac Surg 2006;81(02):619-624 https:// pubmed.ncbi.nlm.nih.gov/16427862/

20 Porte RJ, Molenaar IQ, Begliomini B, et al; EMSALT Study Group. Aprotinin and transfusion requirements in orthotopic liver transplantation: a multicentre randomised double-blind study. Lancet 2000;355(9212):1303-1309 https://pubmed.ncbi.nlm.nih.gov/ $10776742 /$

21 Cardigan RA, Mackie IJ, Gippner-Steppert C, Jochum M, Royston D, Gallimore MJ. Determination of plasma aprotinin levels by functional and immunologic assays. Blood Coagul Fibrinolysis 2001; 12(01):37-42 https://pubmed.ncbi.nlm.nih.gov/11229825/

22 Royston D, Cardigan R, Gippner-Steppert C, Jochum M. Is perioperative plasma aprotinin concentration more predictable and constant after a weight-related dose regimen? Anesth Analg / journal-title>2001;92(04):830-836 https://pubmed.ncbi.nlm. nih.gov/11273910/

23 Beath SM, Nuttall GA, Fass DN, Oliver WC Jr, Ereth MH, Oyen LJ. Plasma aprotinin concentrations during cardiac surgery: fullversus half-dose regimens. Anesth Analg 2000;91(02):257-264

24 Lavee J, Savion N, Smolinsky A, Goor DA, Mohr R. Platelet protection by aprotinin in cardiopulmonary bypass: electron microscopic study. Ann Thorac Surg 1992;53(03):477-481 https:// pubmed.ncbi.nlm.nih.gov/1371665/

25 Wildevuur CRH, Eijsman L, Roozendaal KJ, Harder MP, Chang M, van Oeveren W. Platelet preservation during cardiopulmonary bypass with aprotinin. Eur J Cardiothorac Surg 1989;3(06):533-537, discussion 537-538 https://pubmed.ncbi.nlm.nih.gov/ 2483979/

26 Huang H, Ding W, Su Z, Zhang W. Mechanism of the preserving effect of aprotinin on platelet function and its use in cardiac surgery. J Thorac Cardiovasc Surg 1993;106(01):11-18 https:// pubmed.ncbi.nlm.nih.gov/7686594/

27 Okita Y, Takamoto S, Ando M, et al. Coagulation and fibrinolysis system in aortic surgery under deep hypothermic circulatory arrest with aprotinin: the importance of adequate heparinization. Circulation 1997;96(9, Suppl)II-376-II-381 https://pubmed.ncbi. nlm.nih.gov/9386127/

28 Day JRS, Punjabi PP, Randi AM, Haskard DO, Landis RC, Taylor KM. Clinical inhibition of the seven-transmembrane thrombin receptor (PAR1) by intravenous aprotinin during cardiothoracic surgery. Circulation 2004;110(17):2597-2600 https://pubmed.ncbi. nlm.nih.gov/15262827/

29 Chabbat J, Porte P, Tellier M, Steinbuch M. Aprotinin is a competitive inhibitor of the factor VIIa-tissue factor complex. Thromb Res 1993;71(03):205-215 https://pubmed.ncbi.nlm.nih.gov/ 7692618/

30 Meltzer ME, Lisman T, Doggen CJM, de Groot PG, Rosendaal FR. Synergistic effects of hypofibrinolysis and genetic and acquired risk factors on the risk of a first venous thrombosis. PLoS Med 2008;5(05):e97

31 Lisman T. Decreased Plasma Fibrinolytic Potential As a Risk for Venous and Arterial Thrombosis. Semin Thromb Hemost 2017;43 (02):178-184

32 Hemker HC, Giesen P, AlDieri R, et al. The calibrated automated thrombogram (CAT): a universal routine test for hyper- and hypocoagulability. Pathophysiol Haemost Thromb 2002;32(56):249-253

33 Bar Barroeta A, van Galen J, Stroo I, Marquart JA, Meijer AB, Meijers JCM. Hydrogen-deuterium exchange mass spectrometry highlights conformational changes induced by factor XI activation and binding of factor IX to factor XIa. J Thromb Haemost 2019;17 (12):2047-2055 https://pubmed.ncbi.nlm.nih.gov/31519061/

34 Lisman T, Moschatsis S, Adelmeijer J, Nieuwenhuis HK, De Groot PG. Recombinant factor VIIa enhances deposition of platelets with congenital or acquired $\alpha$ IIb $\beta 3$ deficiency to endothelial cell matrix and collagen under conditions of flow via tissue factorindependent thrombin generation. Blood 2003;101(05): 1864-1870 
35 Huskens D, Li L, Florin L, et al. Flow cytometric analysis of platelet function to improve the recognition of thrombocytopathy. Thromb Res 2020;194:183-189 https://pubmed.ncbi.nlm.nih.gov/32788114/

36 Sharma V, Fan J, Jerath A, et al. Pharmacokinetics of tranexamic acid in patients undergoing cardiac surgery with use of cardiopulmonary bypass. Anaesthesia 2012;67(11):1242-1250 https:// pubmed.ncbi.nlm.nih.gov/22827564/

37 Grassin-Delyle S, Tremey B, Abe E, et al. Population pharmacokinetics of tranexamic acid in adults undergoing cardiac surgery with cardiopulmonary bypass. Br J Anaesth 2013;111(06): 916-924 https://pubmed.ncbi.nlm.nih.gov/23880099/
38 España F, Estelles A, Griffin JH, Aznar J, Gilabert J. Aprotinin (trasylol) is a competitive inhibitor of activated protein C. Thromb Res 1989;56(06):751-756 https://pubmed.ncbi.nlm. nih.gov/2483763/

39 Christensen U, Schiødt J. Effects of aprptinin on coagulation and fibrinolysis enzymes. Fibrinolysis Proteolysis 1997;11(04): 209-214 https://doi.org/10.1016/S0268-9499(97)80052-5

40 Fredenburgh JC, Weitz JI. New anticoagulants: Moving beyond the direct oral anticoagulants. J Thromb Haemost 2021;19(01):20-29 https://pubmed.ncbi.nlm.nih.gov/33047462/ 